\title{
Tribological properties of hot pressing alumina matrix ceramic materials improved by Zr-O-B compounds
}

\author{
Bin $\mathrm{Li}^{\mathrm{i}^{\star}}$, Yonggang Wang ${ }^{2}$, Hong $\mathrm{Li}^{1}$, Huiyuan $\mathrm{You}^{1}$ \\ ${ }^{1}$ School of Mechanical Engineering, Luoyang Institute of Science and Technology, Luoyang 471023, \\ Henan Province, PR China \\ ${ }^{2}$ School of Environmental Engineering and Chemistry, Luoyang Institute of Science and Technology, \\ Luoyang 471023, Henan Province, PR China \\ * Corresponding author; Tel: +86 15937911896; E-mail: libinman@gmail.com (Bin Li)
}

Keywords: Alumina; Zr-O-B compounds; Wear.

\begin{abstract}
Al}_{2} \mathrm{O}_{3} / \mathrm{ZrB}_{2} / \mathrm{ZrO}_{2}$ composites were fabricated by hot pressing technology. The friction and wear behavior of this new material, coupled with cemented carbide ball in unlubricated conditions, were investigated. Experimental results showed that the friction coefficient values and wear rate of alumina matrix ceramic composites toughened by Zr-O-B compounds were lower than that of pure alumina. The generated lubricating film can decrease the friction coefficient of the composites, and makes the wear rate did not reach the theory value.
\end{abstract}

\section{Introduction}

Nowadays, composites made of advanced ceramics can survive and perform well at higher operating temperature, and improve the wear resistance. They are widely applied in the fields of high temperature measuring implement, cutting tools, working platform and high-speed bearing, etc., where high temperature durability and long working life are required. Among these advanced ceramics, alumina matrix ceramic materials are widely selected due to their virtues of high hardness, good chemical inertness, high wear resistance, low coefficient of thermal expansion and friction coefficient. However, the brittleness of pure $\mathrm{Al}_{2} \mathrm{O}_{3}$ limits its potential applications [1-5]. Cemented carbides have outstanding properties of high levels of hardness and wear resistance. The advent of cemented carbides began with the idea of replacing costly diamond wire drawing dies for tungsten filaments. After that, attention was drawn to better cutting tools and finally to a variety of wear parts and machine components [6-7].

The tribological behaviour of alumina has been the topic of many investigations during the last decades. The reason is not only owing to remarkable tribological characteristics of alumina, but also the behavior is greatly influenced by incorporating other elements, changing contact load and speed, temperature, counterface materials, environment, and so on [8-10]. Though many achievements made in tribology of alumina, it is noted that most of these studies were focused on the tribological behaviour of alumina sliding against ceramic or steel [11-12], and there are few articles reporting the tribological properties of alumina or reinforced alumina ceramic sliding against cemented carbides. The enormous cost of tribological deficiencies to any national economy is mostly caused by the large number of energy and material losses occurring simultaneously on virtually every mechanical device in operation. When reviewed on the basis of a single machine, the losses are small. However when the same loss is repeated on perhaps a million machines of a similar type, then the cost becomes very large [13].

In our previous investigations, the introduction of $\mathrm{Zr}-\mathrm{O}-\mathrm{B}$ compounds into alumina matrix can change the fracture mode [14]. However, few papers reported the tribological properties of Zr-O-B compounds reinforced alumina ceramic sliding against cemented carbides, which would be useful in special engineering contact, such as bearings and rails. From the above point of view, this study aims at the influences of sliding velocity and normal load values on the friction and wear behaviour of 
alumina reinforced with $\mathrm{ZrB}_{2} / \mathrm{ZrO}_{2}$ compounds sliding against cemented carbides are studied. In particular, the wear mechanisms and microstructure characteristics are discussed.

\section{Experimental section}

The employed raw materials were high purity $\mathrm{Al}_{2} \mathrm{O}_{3}$ powder having small grain size of about $500 \mathrm{~nm}$. In the $\mathrm{Zr}-\mathrm{O}-\mathrm{B}$ compounds, the content of $\mathrm{ZrB}_{2}$ is $92.2 \% \pm 0.1 \%$ by volume, the content of $\mathrm{ZrO}_{2}$ is $7.8 \% \pm 0.1 \%$ by volume. The particle size of the compounds is about $0.5-1 \mu \mathrm{m}$. The compositions and mechanical properties of the composite materials are shown in Table 1. The suffix in AZ0, AZ10, AZ20, AZ30 and AZ40 represented the volume content of Zr-O-B compounds. For example, AZ0 means the weight content of $\mathrm{Zr}-\mathrm{O}-\mathrm{B}$ compounds is zero.

Table 1 : Compositions and mechanical properties of the AZ series materials

\begin{tabular}{cccccc}
\hline Specimen & Compositions (vol. \%) & $\begin{array}{c}\text { Relative } \\
\text { density (\%) }\end{array}$ & $\begin{array}{c}\text { Bending } \\
\text { strength (MPa) }\end{array}$ & $\begin{array}{c}\text { Hardness (GPa) } \\
\text { toughness } \\
\left(\mathrm{MPa} \mathrm{m}^{1 / 2} \text { ) }\right.\end{array}$ \\
\hline $\mathrm{AZ0}$ & $100 \% \mathrm{Al}_{2} \mathrm{O}_{3}$ & $92.6_{-1.3}^{+0.9}$ & $353.1_{-30.2}^{+28.7}$ & $16.2_{-0.4}^{+0.5}$ & $3.28_{-0.28}^{+0.23}$ \\
$\mathrm{AZ10}$ & $90 \% \mathrm{Al}_{2} \mathrm{O}_{3}+10 \% \mathrm{ZrB}_{2} / \mathrm{ZrO}_{2}$ & $96.4_{-1.2}^{+1.6}$ & $621.7_{-36.6}^{+36.9}$ & $24.0_{-0.5}^{+0.8}$ & $5.11_{-0.29}^{+0.32}$ \\
$\mathrm{AZ20}$ & $80 \% \mathrm{Al}_{2} \mathrm{O}_{3}+20 \% \mathrm{ZrB}_{2} / \mathrm{ZrO}_{2}$ & $98.7_{-0.8}^{+0.9}$ & $760.9_{-38.2}^{+42.1}$ & $23.1_{-0.6}^{+0.6}$ & $6.19_{-0.37}^{+0.25}$ \\
$\mathrm{AZ30}$ & $70 \% \mathrm{Al}_{2} \mathrm{O}_{3}+30 \% \mathrm{ZrB}_{2} / \mathrm{ZrO}_{2}$ & $93.6_{-0.9}^{+1.4}$ & $615.4_{-48.3}^{+45.9}$ & $19.5_{-0.2}^{+0.4}$ & $5.14_{-0.33}^{+0.28}$ \\
$\mathrm{AZ40}$ & $60 \% \mathrm{Al}_{2} \mathrm{O}_{3}+40 \% \mathrm{ZrB}_{2} / \mathrm{ZrO}_{2}$ & $98.7_{-0.6}^{+1.0}$ & $557.8_{-35.5}^{+33.8}$ & $18.7_{-0.6}^{+0.3}$ & $4.79_{-0.26}^{+0.19}$ \\
\hline
\end{tabular}

Friction and wear tests were carried out in a ball-on-disc tribology tester (UMT Multi-Specimen Test System, Center for Tribology, Campbell CA 95008, USA). The contact schematic image for frictional couple is shown in Fig. 1.

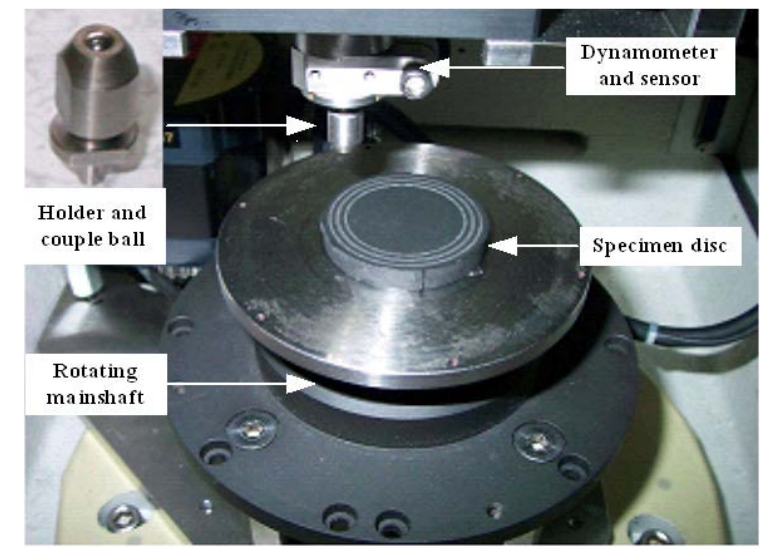

Fig. 1. UMT Multi-Specimen Test System (Center For Tribology, USA).

The diameter of couple ball was $4 \mathrm{~mm}$, and the material is WC cemented carbides. The specimen discs were grinded by vertical spindle grinder and polished with diamond paste to an average surface roughness of $50 \mathrm{~nm}$. The dimension of the specimen disc was $\varnothing 42 \mathrm{~mm} \times 6.5 \mathrm{~mm}$. Friction force could be directly attained from the test system. Friction coefficient was caclculated by tribology tester. A moving average was used to report the Friction coefficient, because the sensitivity of the sensor to both the normal and horizontal forces resulted in some scatters for the data. The white light interferometer (Wyko NT9300, Veeco Corporation, USA) is shown in Fig. 2, which can provide a fast, high-precision three-dimensional surface topography, and the precision can be reach to $0.1 \mathrm{~nm}$ in the vertical scanning range for measurement function. 


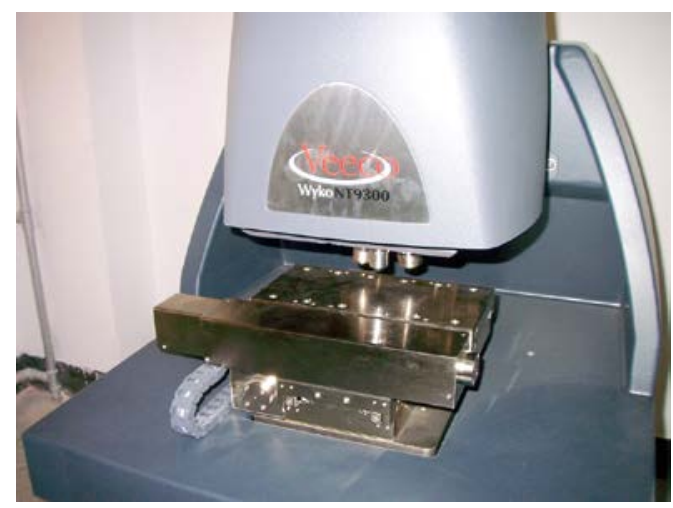

Fig. 2. White light interferometer (Wyko NT9300, Veeco, USA).

\section{Results and discussion}

After friction and wear tests, the measured friction coefficient of AZ0, AZ10, AZ20, AZ30 and AZ40 at the liner speed of $1.33 \mathrm{~m} / \mathrm{s}$ and normal load of $6 \mathrm{~N}$ are shown in Figs. 4. It is evident that, the increasing of $\mathrm{ZrB}_{2} / \mathrm{ZrO}_{2}$ volume content can decrease the friction coefficient of $\mathrm{AZ}$ series composites. This phenomenon may be related to oxidation of $\mathrm{ZrB}_{2}$ materials during the friction and wear tests. It has been investigated in our previous research that the composites began to oxidate at $500^{\circ} \mathrm{C} \sim 700^{\circ} \mathrm{C}$, and the oxidation of $\mathrm{ZrB}_{2}$ follows the reaction: $\mathrm{ZrB}_{2}+5 / 2 \mathrm{O}_{2} \rightarrow \mathrm{ZrO}_{2}+\mathrm{B}_{2} \mathrm{O}_{3}[20]$. The generated $\mathrm{ZrO}_{2}$ and $\mathrm{B}_{2} \mathrm{O}_{3}$ can form a self-lubricating film, which could improve the tribological behavior and prevent the adhesive wear at high temperature. As a result, the higher $\mathrm{ZrB}_{2} / \mathrm{ZrO}_{2}$ compounds, the larger generated $\mathrm{ZrO}_{2}$ and $\mathrm{B}_{2} \mathrm{O}_{3}$, and which may be contribute to decreasing the friction coefficient of $\mathrm{AZ}$ series composites.

Wear rates vs. $\mathrm{ZrB}_{2} / \mathrm{ZrO}_{2}$ volume content for $\mathrm{AZ}$ series composites when dry sliding against cemented carbides is plotted in Fig. 5. Addition of $\mathrm{ZrB}_{2} / \mathrm{ZrO}_{2}$ compounds promote the densification rate of the composites, decrease interspaces or cavities, enhance the hardness and fracture toughness, and thus lead to better wear resistance. It can be observed from Fig. 5 that the wear rate of AZ20 specimen is lower than that of AZ0 and AZ40. On the one hand, the value of wear rate mainly depends on the hardness of the composites. Higher hardness brings on lower wear rate and they are inverse ratio. The hardness of AZ0 is $15.3 \mathrm{GPa}$, and AZ40 is $18.2 \mathrm{GPa}$, they are lower than that of AZ20 with 23.1GPa. So the wear rate increase as the hardness of composites decreases. On the other hand, when the content of $\mathrm{ZrB}_{2} / \mathrm{ZrO}_{2}$ is less than $20 \%$, the $\mathrm{ZrO}_{2}$ can play an active role in toughening the matrix by phase transformation technology. But, with the increase of $\mathrm{ZrB}_{2} / \mathrm{ZrO}_{2}$ ratio, more $\mathrm{ZrB} 2$ will oxidize in this condition. A lot of $\mathrm{ZrO}_{2}$ and $\mathrm{B}_{2} \mathrm{O}_{3}$ are in-situ generated, the hardness of the oxidation composites will dramatically decrease as the hardness of $\mathrm{ZrO}_{2}$ itself is about $13 \mathrm{GPa}$. So, AZ20 composite express the better wear resistance in the AZ series materials. 

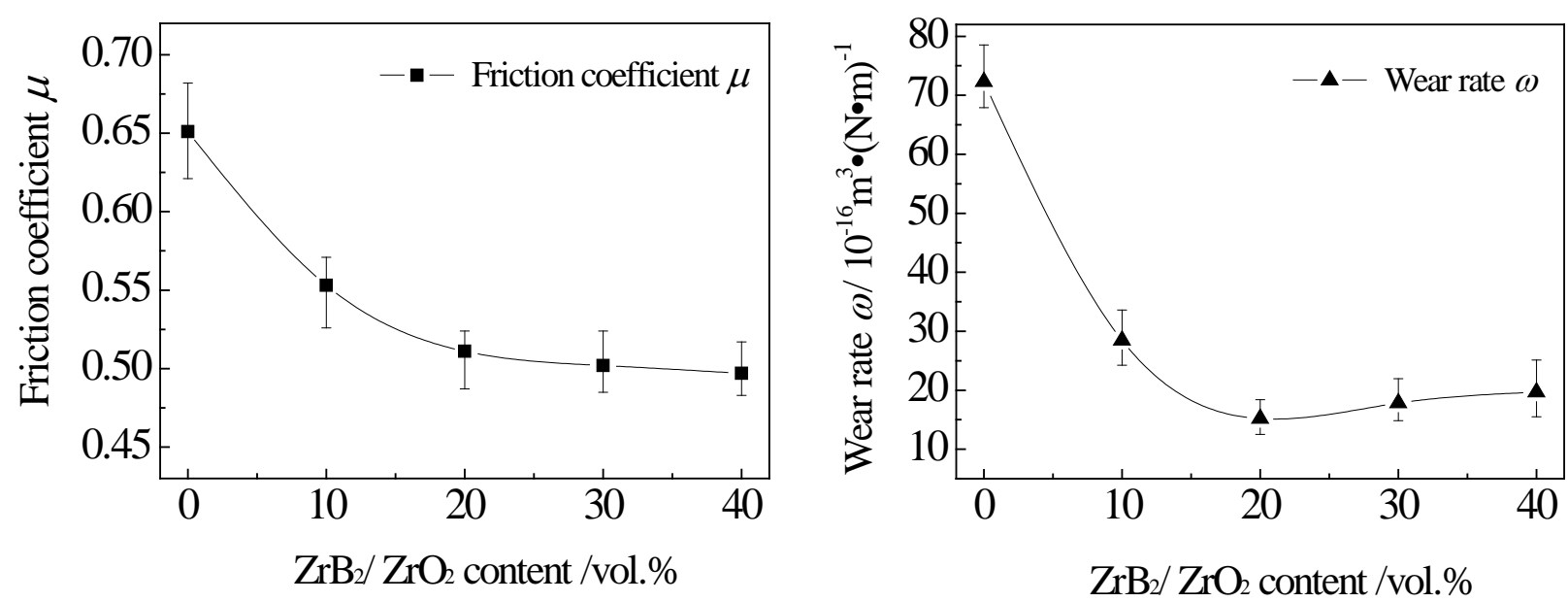

Fig. 5. Relation of $\mathrm{ZrB}_{2} / \mathrm{ZrO}_{2}$ content and friction coefficient. Fig. 6. Relation of $\mathrm{ZrB}_{2} / \mathrm{ZrO}_{2}$ content and wear rate.

\section{Conclusions}

$\mathrm{Al}_{2} \mathrm{O}_{3} / \mathrm{ZrB}_{2} / \mathrm{ZrO}_{2}$ composites were fabricated by hot pressing technology. The friction and wear behavior of this new material, coupled with cemented carbide ball in unlubricated conditions, were investigated. Experimental results showed that the friction coefficient values and wear rate of alumina matrix ceramic composites toughened by $\mathrm{Zr}-\mathrm{O}-\mathrm{B}$ compounds were lower than that of pure alumina. The wear rate of pure alumina was about $7 \times 10^{-15} \mathrm{~m}^{3} / \mathrm{N} \cdot \mathrm{m}$ while that of alumina matrix ceramic composites toughened by $20 \% \mathrm{Zr}-\mathrm{O}-\mathrm{B}$ compounds was about $1.5 \times 10^{-15} \mathrm{~m}^{3} / \mathrm{N} \cdot \mathrm{m}$. The mechanism responsible was explained as the formation of a lubricating film between the sliding couple, and the composition of this lubricating film was found to be $\mathrm{ZrO}_{2}$ and $\mathrm{B}_{2} \mathrm{O}_{3}$. The generated lubricating film can decrease the friction coefficient of the composites, and makes the wear rate did not reach the theory value.

\section{Acknowledgements}

The work described in this paper is supported by the National Natural Science Foundation of China (No.51475222), the Science and Technology Development Foundation of Henan Province (No.132102210514), the Outstanding Youth Innovation Foundation for Science and Technology of Henan province (No.144100510017), the International Cooperation Projects for Science and Technology of Henan province (No.144300510050), the Young Backbone Teachers Foundation for the Universities of Henan Province (No.2013GGJS-186) and the Development Program for Science and Technology of Luoyang (No.1202016A).

\section{References}

[1] JP Buban; K Matsunaga; J Chen; N Shibata; WY Ching; T Yamamoto; Y Ikuhara. Science, 2006, 311(5758), 212-215.

[2] BT Lee; SK Sarkar; HY Song. J. Eur. Ceram. Soc., 2008, 28(1), 229-233.

[3] B Smuk; M Szutkowska; J. Walter. J. Mater. Process. Tech., 2003, 133(1-2), 195-198.

[4] JX Deng; TK. Cao; LL Liu. J. Eur. Ceram. Soc., 2005, 25(7), 1073-1079.

[5] E Laarz; M Carlsson; B Vivien; M Johnsson; M Nygren; L. Bergstrom. J. Eur. Ceram. Soc., 2001, 21(8), 1027-1035.

[6] G Upadhyaya. Cemented tungsten carbides: production, properties, and testing, New Jersey, Noyes Pubns, 1998. 
[7] NG Hashe; JH Neethling; HO Andrén; S Norgren; and PR Berndt. Int. J. Refract. Met. Hard Mater. 2008, 26(5), 404-410.

[8] H Dong; T Bell. Wear. 1999, 225-229(Part 2), 874-884.

[9] V Ucar; A Ozel; A Mimaroglu; I CallI; M Gur. Materials \& Design. 2001, 22(3), 171-175.

[10] T Murakami; K Umeda; S Sasaki; J Ouyang. Tribology International. 2006, 39(12), 1576-1583.

[11] K Poser; KHZ Gahr; J Schneider. Wear. 2005, 259(1-6), 529-538.

[12] L Esposito; A Tucci. Wear. 1997, 205(1-2), 88-96.

[13] B Li; JX Deng. Journal of Alloys and Compounds. 2009, 473(1-2), 190-194.

[14] B Li; JX Deng; YS Li. International Journal of Refractory Metals and Hard Materials. 2009, 27(4), 747-753. 